\title{
Journal Of Pharmacy And Experimental Medicine
}

\section{Efficacy of Empagliflozin in Reducing Cardiovascular Risk and Glycemic Control in Long Standing Diabetic Patients: An Observational Study}

\author{
S Divya $\odot^{\circ}$, Devarakonda Sivakumar $\odot^{1}$, D. Likhitha $\odot^{1}$, K. Sravani $\odot^{1}$, S. Priya $\odot^{1}$ \\ "Department of Pharmacy Practice, Ratnam Institute of Pharmacy, Nellore, Andhra Pradesh \\ ${ }^{1}$ Pharm D, Ratnam Institute of Pharmacy, Nellore, Andhra Pradesh
}

\section{A $\quad$ R $T$ T I C L}

\section{Article history:}

Received 20 Febraury 2021

Accepted 03 March 2021

Revised 09 March 2021

Available online 15 March 2021

Keywords:

Diabetes mellitus

SGLT2 inhibitors

Empagliflozin

Glycemic control

Cardiovascular risk

\begin{abstract}
A $\quad$ B $\quad S \quad T \quad R \quad A \quad C \quad T$
Diabetes mellitus is a heterogeneous complex metabolic disorder characterized by elevated blood glucose concentrations. The chronic hyperglycemia of diabetes is associated with long-term damage, dysfunction and failure of various organs. This is a leading health disorder with rising prevalence day by day with irrespective of age and gender. The diabetes patients are prone to have cardiovascular risk such as dyslipidemia, hypertension, coronary artery disease, obesity. The management of diabetes mellitus includes insulin and oral anti-diabetic agents. Among them Sodium glucose co-transporter 2 inhibitors are effective in achieving glycemic control in long-standing diabetic patients as single or add-on therapy. A large number of studies had proven that empagliflozin which belongs to the class SGLT2 inhibitors had shown potent glycemic control and reduces the cardiovascular risk in long-standing diabetic patients.
\end{abstract}

(c) 2021, . S Divya, Devarakonda Sivakumar, D. Likhitha, K. Sravani, S. Priya. This is an open-access article distributed under the terms of the Creative Commons Attribution 4.0 International License, which permits unrestricted use, distribution and reproduction in any medium, provided the original author and source are credited

\section{Introduction}

Diabetes mellitus (DM) refers to a group of common and chronic metabolic disorder that shares the phenotype of hyperglycemia. Several distinct types of DM are caused by a complex interaction of a genetics and environmental factors. Coming to the history of type-2 diabetes, it is described as a metabolic syndrome firstly in 1988 [1]. Usually type 2 diabetes arises due to interaction between different factors such as environmental, social habits and genetic factors $[2,3]$. The metabolic dys-regulation associated with DM causes secondary pathophysiology changes in multiple organ system that imposed a tremendous burden on the individuals with diabetes and on the health care system. According to 2011 census, due to the cause of diabetes 4.6 million deaths were noted [4].

\section{Classification}

Diabetes is a heterogeneous, complex metabolic disorder characterized by elevated blood glucose concentrations secondary to either resistance to the action of insulin, insufficient insulin secretion or both. The chronic hyperglycemia of diabetes is associated with long term damage, dysfunction and failure of various organs, especially the eyes, kidneys, nerves, heart, and blood vessels. A wide spread

Corresponding author

S Divya, Department of Pharmacy Practice, Ratnam Insti-

tute of Pharmacy, Nellore, Andhra Pradesh, India.

E-mail address: hari1509@gmail.com pathological change is thickening of capillary basement membrane, increase in vessel wall matrix and cellular proliferation resulting in vascular complications like lumen narrowing, early atherosclerosis, sclerosis of glomerular capillaries and peripheral vascular insufficiency. According to American Diabetes Association (ADA) 1997, the Diabetes classification includes: 1 . Type 1 diabetes mellitus, 2. Type 2 diabetes mellitus, 3. Gestational diabetes and still it is most widely accepted classification [5].

\section{Study Design and Methodology}

\subsection{Aim of the study}

To conduct an observational study on efficacy of Empagliflozin [SGLT2 inhibitor] in reducing cardiovascular risk and achieving glycaemic control in long standing diabetes patients who are on more than two Anti-diabetic therapy.

\subsection{Type of study}

Observational study

3.4 Place of Study

ACSR Government General Hospital Nellore

3.5 Period of the study

6 months [July 2019 to November 2019]

3.6 Study Population

40 Patients 


\subsection{Patient Enrolment}

Patients enrolled in the study based on the inclusion and exclusion criteria.

\subsubsection{Inclusion criteria}

- Patient's with age between 35-85 years.

- Patient having history of T2DM

- Patient having co-morbidities of hypertension and other cardiovascular related ones.

- Patient's who were willing to take the drug.

- Patient having stable background anti-hyperglycemic therapy.

- Patient's who were on dual or triple therapy. (Metformin, sulfonylureas and gliptins)

\subsubsection{Exclusion criteria}

- Patient's who are not willing to take the drug.

- Patient using SGLT2: GLP-IRA/ saxagliptin.

- Patient having GFR $<60 \mathrm{ml} / \mathrm{min} / 1.73 \mathrm{~m} 2$

- Patient having LVEF $<30 \%$.

- Patient's with NYHA class 4 or recent HHF.

- Pregnancy and lactation mothers were excluded.

\section{Clinical Manifestations}

The person with diabetes mellitus mainly present frequent urination, Dry mouth, repeated infections, blurred vision, fatigue, susceptibility to certain infections, slow wound healing, numbness in soles and palms, tingling, acanthosis nigricans (rarely), weight loss [6].

\section{Pharmacological Treatment}

\section{a) Insulin therapy}

Insulin therapy is a critical part of treatment for people with type 1 diabetes and also for many with type 2 diabetes. The goal of therapy is to keep blood sugar levels within the target range. It is administered by subcutaneous route, it been always a drawback for insulin to inject into the body. Oral hypoglycemic agents are also used in lowering the blood glucose level. Insulin should be initiated when A1c is greater than $7 \%$ after 2-3 months of dual oral therapy [7].

\section{b) Oral anti diabetic drugs}

$>$ Sulphonylureas

$>$ Biguanide

$>$ Thiazolidinediones

$>$ Dipeptidyl peptides-4 Inhibitors

$>$ Meglitinide Sodium glucose cotransporter-2(SGLT-2) inhibitor

$>$ Dopamine D2 agonist

\subsection{Sodium-Glucose Cotransporter Inhibitors (SGLT Inhibitors)}

Sodium-dependent glucose co-transporters/sodium glucose linked transporter are family of glucose transporters, SGLT localization is different according to their types and listed in Table 1 . These are the latest class of diabetic drugs received FDA approval [8].

Table 1: SGLT family, substrates and their distribution in tissues

\begin{tabular}{|c|c|c|}
\hline SGLT Family & Substrates & Distribution in tissues \\
\hline SGLT1 & Glucose, galactose & $\begin{array}{c}\text { Intestine, trachea, kidney, heart, } \\
\text { brain, testis, prostate. }\end{array}$ \\
\hline SGLT2 & glucose & $\begin{array}{c}\text { Kidney, brain, liver, thyroid, } \\
\text { muscle, heart. }\end{array}$ \\
\hline SGLT3 & glucose & $\begin{array}{c}\text { Intestine, testis, uterus, lung, } \\
\text { thyroid, brain. }\end{array}$ \\
\hline SGLT4 & Glucose, mannose & $\begin{array}{c}\text { Intestine, kidney, liver, brain, lungs, } \\
\text { trachea, pancreas, uterus. }\end{array}$ \\
\hline SGLT5 & Glucose, galactose & Kidney. \\
\hline
\end{tabular}

\subsection{Clinical Physiology in glucose control}

Sodium-glucose cotransporter-2 (SGLT2) is selectively expressed in the human kidney, where it executes re-absorption of filtered glucose with a high capacitance; it may be over active in patients with diabetes especially in the hyper filtering stage of the disease. As a therapeutic target, SGLT2 has been successfully engaged by orally active selective agents and described the use in glucose control in Figure 1. In a metaanalysis published in 2014, 24 week reduction of HbA1C with SGLT2 inhibitors in trials enrolled patients with higher baseline BMI, HbA1C, and fasting glucose results better outcome [9].

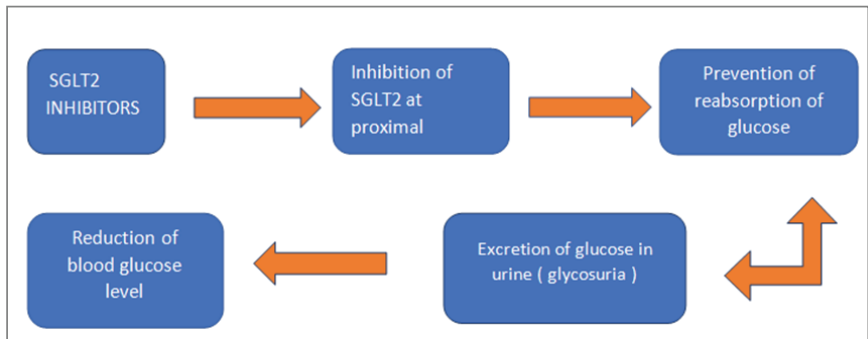

Figure 1: SGLT 2 Inhibitors role in glucose control

\subsection{SGLT2 Inhibitors - Cardiovascular Protection}

Sodium-glucose cotransporter 2 (SGLT2) Inhibitors have demonstrated precedent cardiovascular benefits in large scale clinical trials of people who have type 2 diabetes mellitus and established cardiovascular disease or multiple cardiovascular risk factors. In the empagliflozin cardiovascular outcome event trail in type 2 diabetes mellitus patients - remove excess glucose (EMPA-REG Outcome) study [10], 7020 individuals with type 2 diabetes who had coronary, peripheral cardiovascular disease or cerebrovascular disease were randomized to receive the SGLT2 inhibitor empagliflozin or placebo, while the primary three-point major adverse cardiac events outcome (cardiovascular death, nonfatal myocardial infarction and non-fatal stroke) was significantly attenuated by empagliflozin, which was particularly noteworthy and the early effects of empagliflozin on cardiovascular death and hospitalization for heart failure, which were reduced by $38 \%$ and $35 \%$ respectively and in addition all -cause mortality was reduced by $32 \%$. Mechanisms underlying in this function as follows:

- Improvement in cardiac metabolism and bioenergetics.

- Myocardial $\mathrm{Na}+/ \mathrm{H}+$ exchange inhibition.

- Reduction in necrosis and cardiac fibrosis.

- Alteration in adipokines, cytokine protein production and epicardial adipose tissue mass.

6. Plan of Study

Our plan study was depicted in flow chart. It gives an idea about how we worked on our project.

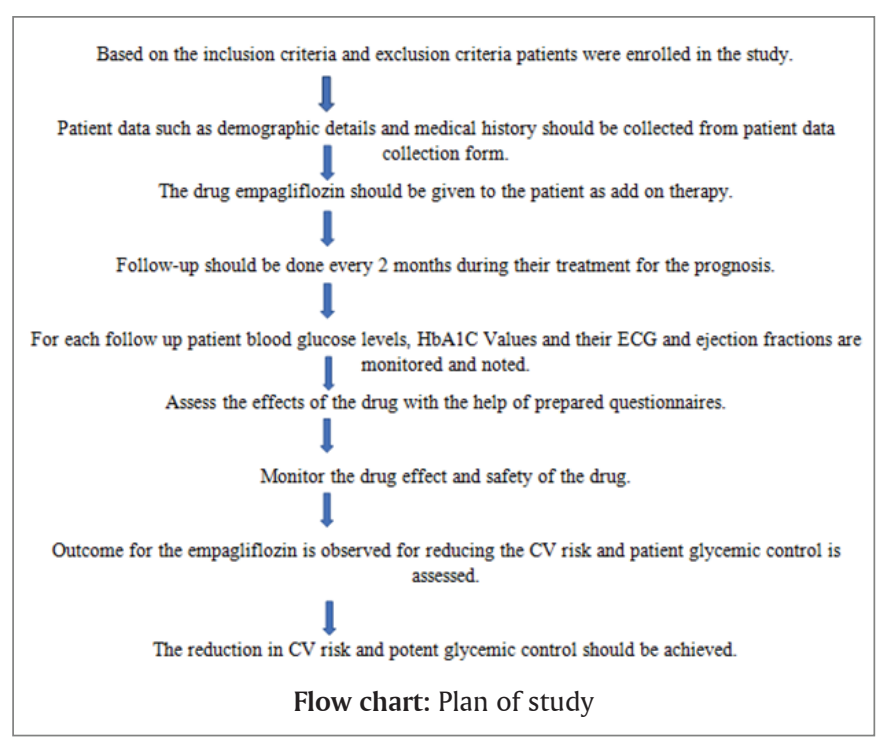


Divya S et al. / Journal Of Pharmacy And Experimental Medicine

\section{Results and Discussion}

\subsection{Categorized based on age}

Out of 40 patients 7 belong to $35-45$ years; 17 belong to $46-55$ years; 5 belong to $56-65$ years; 4 belong to $66-75$ years; 7 belong to 76-85 years.

\subsection{Categorized based on gender}

Among 70 patients 24 were males and 16 were females.

\subsection{Categorized based on co-morbidities}

Distribution based on co-morbidities, out of 40 members the patients with co-morbidities were 16 and the patients without comorbidities were 24 .

\subsection{Categorized based on duration of type $2 \mathrm{DM}$}

Among 40 patients 16 patients has 6-10 years of duration of type

Table 2: Patient's data of glucose levels according to their visits
2 diabetes mellitus; 18 patients has 11-15 years of duration of type 2 diabetes mellitus; 5 patients has $16-20$ years of duration of type 2 diabetes mellitus; and 1 patient has $>20$ years of duration of type 2 diabetes mellitus.

\subsection{Categorized based on Social habits}

Among total subjects 10 were alcoholics; and 2 were smokers.

\subsection{Patient's data during Observational study}

Patient's data was tabulated in Table 2 with respective to their visits and glucose levels in order to support the glycemic control of Empagliflozin. Patient's data was tabulated in Table 3 with respective to their ejection factor in order to support the cardiovascular protection of Empagliflozin.

\begin{tabular}{|c|c|c|c|c|c|}
\hline S.No & values & Visit-1 & Visit-2 & Visit-3 & Visit-4 \\
\hline \multirow[b]{3}{*}{1.} & FBS & 210 & 189 & 149 & 183 \\
\hline & PPBS & 301 & 262 & 179 & 120 \\
\hline & HbA1c & 10.6 & 9.3 & 6.8 & 4.2 \\
\hline \multirow[b]{3}{*}{2.} & FBS & 239 & 152 & 128 & 103 \\
\hline & PPBS & 343 & 241 & 172 & 142 \\
\hline & HbA1c & 12.1 & 8.1 & 6.2 & 5.10 \\
\hline \multirow[b]{3}{*}{3.} & FBS & 186 & 154 & 102 & 94 \\
\hline & PPBS & 296 & 190 & 172 & 136 \\
\hline & HbA1c & 10 & 7.1 & 5.75 & 4.7 \\
\hline \multirow[b]{3}{*}{4.} & FBS & 204 & 170 & 110 & 74 \\
\hline & PPBS & 326 & 190 & 170 & 142 \\
\hline & HbA1c & 11.4 & 7.5 & 5.8 & 4.5 \\
\hline \multirow{3}{*}{5.} & FBS & 265 & 182 & 172 & 158 \\
\hline & PPBS & 342 & 280 & 194 & 172 \\
\hline & HbA1c & 12.6 & 9.6 & 7.6 & 6.8 \\
\hline \multirow{3}{*}{6.} & FBS & 178 & 149 & 119 & 76 \\
\hline & PPBS & 281 & 222 & 183 & 130 \\
\hline & HbA1c & 9.5 & 7.7 & 6.2 & 4.2 \\
\hline \multirow{3}{*}{7.} & FBS & 200 & 169 & 145 & 120 \\
\hline & PPBS & 259 & 224 & 201 & 170 \\
\hline & HbA1c & 9.3 & 8.1 & 7.2 & 6.0 \\
\hline \multirow{3}{*}{8.} & FBS & 180 & 152 & 120 & 85 \\
\hline & PPBS & 240 & 210 & 162 & 138 \\
\hline & HbA1c & 8.7 & 7.5 & 5.8 & 4.4 \\
\hline \multirow{3}{*}{9.} & FBS & 195 & 160 & 127 & 100 \\
\hline & PPBS & 250 & 210 & 180 & 140 \\
\hline & HbA1c & 9.2 & 7.70 & 6.3 & 5 \\
\hline \multirow{3}{*}{10.} & FBS & 220 & 180 & 135 & 114 \\
\hline & PPBS & 296 & 240 & 176 & 150 \\
\hline & HbA1c & 10.7 & 8.7 & 6.4 & 5.5 \\
\hline \multirow{3}{*}{11.} & FBS & 212 & 184 & 130 & 90 \\
\hline & PPBS & 224 & 210 & 162 & 138 \\
\hline & HbA1c & 9.0 & 8.2 & 6.0 & 4.7 \\
\hline \multirow{3}{*}{12.} & FBS & 230 & 158 & 110 & 96 \\
\hline & PPBS & 331 & 227 & 157 & 118 \\
\hline & $\mathrm{HbA1c}$ & 11.6 & 8.0 & 5.5 & 4.4 \\
\hline \multirow{3}{*}{13.} & FBS & 246 & 172 & 146 & 106 \\
\hline & PPBS & 358 & 256 & 209 & 155 \\
\hline & HbA1c & 12.5 & 8.8 & 7.3 & 5.4 \\
\hline \multirow{3}{*}{14.} & FBS & 260 & 179 & 162 & 108 \\
\hline & PPBS & 320 & 280 & 176 & 148 \\
\hline & HbA1c & 12.5 & 9.5 & 7.1 & 5.3 \\
\hline
\end{tabular}


Divya S et al. / Journal Of Pharmacy And Experimental Medicine

\begin{tabular}{|c|c|c|c|c|c|}
\hline \multirow{3}{*}{15.} & FBS & 212 & 200 & 164 & 114 \\
\hline & PPBS & 354 & 236 & 186 & 140 \\
\hline & HbA1c & 11.7 & 9.0 & 7.2 & 5.2 \\
\hline \multirow{3}{*}{16.} & FBS & 289 & 182 & 139 & 108 \\
\hline & PPBS & 384 & 280 & 200 & 144 \\
\hline & HbA1c & 14.0 & 9.6 & 8.5 & 5.2 \\
\hline \multirow{3}{*}{17.} & FBS & 232 & 168 & 129 & 105 \\
\hline & PPBS & 406 & 289 & 236 & 140 \\
\hline & HbA1c & 13.2 & 9.5 & 7.6 & 5.1 \\
\hline \multirow{3}{*}{18.} & FBS & 286 & 244 & 168 & 116 \\
\hline & PPBS & 353 & 324 & 284 & 162 \\
\hline & HbA1c & 13.3 & 11.8 & 9.4 & 5.7 \\
\hline \multirow{3}{*}{19.} & FBS & 226 & 164 & 114 & 104 \\
\hline & PPBS & 354 & 250 & 164 & 148 \\
\hline & HbA1c & 12.0 & 8.6 & 6.7 & 5.2 \\
\hline \multirow{3}{*}{20.} & FBS & 230 & 175 & 140 & 128 \\
\hline & PPBS & 440 & 340 & 280 & 220 \\
\hline & HbA1c & 13.9 & 10.7 & 8.7 & 7.2 \\
\hline \multirow{3}{*}{21.} & FBS & 260 & 192 & 171 & 132 \\
\hline & PPBS & 354 & 236 & 200 & 156 \\
\hline & HbA1c & 12.7 & 8.9 & 7.7 & 6.0 \\
\hline \multirow{3}{*}{22.} & FBS & 241 & 192 & 186 & 140 \\
\hline & PPBS & 379 & 236 & 220 & 162 \\
\hline & HbA1c & 12.7 & 10.6 & 8.4 & 6.2 \\
\hline \multirow{3}{*}{23.} & FBS & 220 & 196 & 177 & 122 \\
\hline & PPBS & 291 & 250 & 200 & 170 \\
\hline & HbA1c & 10.6 & 9.2 & 7.8 & 6.0 \\
\hline \multirow{3}{*}{24.} & FBS & 256 & 216 & 183 & 145 \\
\hline & PPBS & 320 & 296 & 237 & 190 \\
\hline & HbA1c & 12.0 & 10.6 & 8.7 & 7.0 \\
\hline \multirow{3}{*}{25.} & FBS & 196 & 172 & 141 & 123 \\
\hline & PPBS & 259 & 220 & 186 & 152 \\
\hline & HbA1c & 9.4 & 8.2 & 6.8 & 5.7 \\
\hline \multirow{3}{*}{26.} & FBS & 276 & 206 & 187 & 130 \\
\hline & PPBS & 312 & 262 & 201 & 178 \\
\hline & HbA1c & 12.2 & 9.7 & 8.0 & 6.4 \\
\hline \multirow{3}{*}{27.} & FBS & 251 & 215 & 197 & 156 \\
\hline & PPBS & 296 & 246 & 211 & 170 \\
\hline & HbA1c & 11.3 & 9.6 & 8.5 & 6.7 \\
\hline \multirow{3}{*}{28.} & FBS & 306 & 237 & 176 & 154 \\
\hline & PPBS & 416 & 302 & 257 & 190 \\
\hline & HbA1c & 13.9 & 11.2 & 8.5 & 7.1 \\
\hline \multirow{3}{*}{29.} & FBS & 269 & 229 & 190 & 140 \\
\hline & PPBS & 300 & 290 & 230 & 186 \\
\hline & HbA1c & 11.8 & 10.8 & 8.7 & 6.7 \\
\hline \multirow{3}{*}{30.} & FBS & 287 & 229 & 187 & 146 \\
\hline & PPBS & 340 & 290 & 229 & 170 \\
\hline & HbA1c & 13.0 & 10.1 & 8.6 & 6.5 \\
\hline & FBS & 198 & 162 & 157 & 116 \\
\hline 31. & PPBS & 276 & 230 & 196 & 154 \\
\hline 31. & HbA1c & 9.8 & 8.2 & 7.3 & 5.6 \\
\hline & FBS & 230 & 196 & 170 & 130 \\
\hline 32 & PPBS & 310 & 254 & 197 & 168 \\
\hline & HbA1c & 11.2 & 9.3 & 7.6 & 6.2 \\
\hline & FBS & 210 & 177 & 156 & 125 \\
\hline & PPBS & 296 & 239 & 187 & 159 \\
\hline 33. & HbA1c & 10.5 & 9.3 & 7.1 & 5.9 \\
\hline & FBS & 281 & 239 & 181 & 141 \\
\hline 34. & PPBS & 354 & 276 & 200 & 172 \\
\hline 34. & HbA1c & 13.2 & 10.2 & 7.9 & 6.5 \\
\hline
\end{tabular}


Divya S et al. / Journal Of Pharmacy And Experimental Medicine

\begin{tabular}{|c|c|c|c|c|c|}
\hline \multirow{3}{*}{35.} & FBS & 222 & 194 & 177 & 136 \\
\hline & PPBS & 299 & 239 & 201 & 180 \\
\hline & HbA1c & 10.8 & 9.0 & 7.8 & 6.5 \\
\hline \multirow{3}{*}{36.} & FBS & 180 & 169 & 132 & 97 \\
\hline & PPBS & 240 & 210 & 176 & 136 \\
\hline & HbA1c & 8.7 & 7.8 & 6.4 & 4.8 \\
\hline \multirow{3}{*}{37.} & FBS & 200 & 176 & 152 & 114 \\
\hline & PPBS & 259 & 210 & 185 & 142 \\
\hline & HbA1c & 9.5 & 8.0 & 7.0 & 5.3 \\
\hline \multirow{3}{*}{38.} & FBS & 162 & 137 & 110 & 87 \\
\hline & PPBS & 201 & 187 & 154 & 120 \\
\hline & HbA1c & 7.5 & 6.7 & 5.5 & 4.3 \\
\hline \multirow{2}{*}{39.} & FBS & 239 & 196 & 149 & 110 \\
\hline & PPBS & 284 & 245 & 186 & 137 \\
\hline \multirow{3}{*}{40.} & FBS & 178 & 146 & 120 & 76 \\
\hline & PPBS & 275 & 201 & 176 & 130 \\
\hline & HbA1c & 9.3 & 7.2 & 6.1 & 4.2 \\
\hline
\end{tabular}

Using SPSS statistical Software (SPSS 2.0) the probability Value is calculated as:

FBS: $\mathrm{p}$ value is $<0.00001$ and the result is significant at $\mathrm{p}<0.05$

PPBS: $\mathrm{p}$ value is $<0.00001$ and the result is significant at $\mathrm{p}<0.05$

HbA1c: $\mathrm{p}$ value is $<0.00001$ and the result is significant at $\mathrm{p}<0.05$

Table 3: Patient's data of ejection factor before and after initiation of empagliflozin therapy

\begin{tabular}{|c|c|c|c|c|}
\hline \multirow[t]{2}{*}{ S.No } & \multicolumn{2}{|l|}{ ECG } & \multicolumn{2}{|c|}{ EJECTION FRACTION } \\
\hline & before & After & before & After \\
\hline 1. & Abnormal & Better & 54 & 62 \\
\hline 2. & Abnormal & Better & 45 & 69 \\
\hline 3. & Abnormal & Better & 45 & 71 \\
\hline 4. & Abnormal & Better & 39 & 51 \\
\hline 5. & Abnormal & Better & 45 & 63 \\
\hline 6. & Abnormal & Better & 45 & 59 \\
\hline 7. & Abnormal & Better & 39 & 50 \\
\hline 8. & Abnormal & Better & 42 & 67 \\
\hline 9. & Abnormal & Better & 48 & 72 \\
\hline 10. & Abnormal & Better & 62 & 70 \\
\hline 11. & Abnormal & Better & 52 & 68 \\
\hline 12. & Normal & Normal & 70 & 70 \\
\hline 13. & Normal & Normal & 64 & 67 \\
\hline 14. & Normal & Normal & 57 & 59 \\
\hline 15. & Normal & Normal & 68 & 70 \\
\hline 16. & Normal & Normal & 61 & 61 \\
\hline 17. & Normal & Normal & 55 & 58 \\
\hline 18. & Normal & Normal & 57 & 62 \\
\hline 19. & Normal & Normal & 65 & 65 \\
\hline 20. & Normal & Normal & 58 & 60 \\
\hline 21. & Abnormal & Better & 49 & 52 \\
\hline 22. & Normal & Normal & 56 & 57 \\
\hline 23. & Normal & Normal & 65 & 65 \\
\hline 24. & Normal & Normal & 64 & 68 \\
\hline 25. & Normal & Normal & 70 & 70 \\
\hline 26. & Normal & Normal & 55 & 58 \\
\hline 27. & Normal & Normal & 57 & 60 \\
\hline 28. & Normal & Normal & 70 & 71 \\
\hline 29. & Abnormal & Better & 48 & 55 \\
\hline 30. & Normal & Normal & 69 & 70 \\
\hline 31. & Normal & Normal & 57 & 60 \\
\hline 32. & Normal & Normal & 60 & 60 \\
\hline 33. & Normal & Normal & 63 & 65 \\
\hline
\end{tabular}


Divya S et al. / Journal Of Pharmacy And Experimental Medicine

\begin{tabular}{|l|l|l|l|l|}
\hline 34. & Normal & Normal & 59 & 63 \\
\hline 35. & Normal & Normal & 70 & 70 \\
\hline 36. & Normal & Normal & 65 & 65 \\
\hline 37. & Normal & Normal & 64 & 67 \\
\hline 38. & Abnormal & Better & 52 & 68 \\
\hline 39. & Abnormal & Better & 46 & 57 \\
\hline 40. & Abnormal & Better & 45 & 54 \\
\hline
\end{tabular}

From the above data, among 40 subjects; 16 patients had the abnormal ECG and abnormal ejection fraction before initiation of therapy i.e. 16 subjects are having the cardiovascular risk before initiation of Empagliflozin therapy.

\section{Conclusion}

Empagliflozin has a consistent cardio protective effect in patients with T2DM and CVD, regardless of the number of CV risk factors that are controlled. Empagliflozin can be taken along with the other oral anti-diabetes medications such as metformin, sulfonylureas, mono or poly therapy but strict monitoring, awareness regarding dietary modifications are needed during the continuous period of treatment along with the betterment of CV symptoms, empagliflozin was achieved the better glycemic control especially in patients with cardiovascular disease. It is a good alternative to the uncontrolled hyperglycemic patients who are already using triple therapy at maximum dose and not willing to take insulin despite of having minimal adverse effects, it is having very good proven cardiac safety, which makes diabetic management more potent.

\section{Conflict of Interest}

None

\section{Ethical Concern}

We have obtained informed concern from every patient participated in the study.

\section{Source of Funding}

None

Acknowledgements

None

\section{References}

1. Patlak M. New weapons to combat an ancient disease: treating diabetes. FASEB J 2002. Dec;16(4):1853 Doi: 10.1096/fj.02-0974bkt [Pubmed]

2. Chen L, Magliano DJ, Zimmet PZ. The worldwide epidemiology of type 2 diabetes mellitus: present and future perspectives. Nature reviews endocrinology. Available at: www.nature.com/uidfinder (Accessed 12 December 2020) [PubMed]

3. Genetic basis of type 1 and type 2 diabetes, obesity, and their complications. Advances and emerging opportunities in diabetes research: a strategic planning report of the DMICC. (Accessed 12 December 2020) [PubMed]

4. Global burden of diabetes. International Diabetes federation. Diabetic atlas fifth edition 2011, Brussels. Available at http://www.idf. org/diabetesatlas (Accessed 14th December 2020)

5. American Diabetes Association. Diagnosis and classification of diabetes mellitus. Diabetes Care. 2014;37 Suppl 1:S81-90. [PubMed]
6. Alberti KGMM, Zimmet P, Shaw J. International Diabetes Federation: a consensus on type 2 diabetes prevention. Diabet Med. 2007;24:451-63. [PubMed]

7. Geyelin HR, Harrop G, Murray MF, Corwin E. The use of insulin in Juvenile diabetes. J Metabolic Res. 1922;2:767-792. [Google Scholar]

8. D S Hsia, Owen G, W T Cefalu. An Update on SGLT2 Inhibitors for the Treatment of Diabetes Mellitus. Curr Opin Endocrinol Diabetes Obes. 2017 Feb;24(1):73-79. doi: 10.1097/MED.0000000000000311. [PubMed]

9. Monami M, Nardini C, Mannucci E. Efficacy and safety of sodium glucose co-transport- 2 inhibitors in type 2 diabetes: a meta-analysis of randomized clinical trials. Diabetes Obes Metab. 2014 May;16(5):457-66. [PubMed]

10. Zinman B, Wanner C, Lachin JM, Fitchett D, Bluhmki E, Hantel S, et al. Empagliflozin, Cardiovascular outcomes, and Mortality in Type 2 Diabetes. The New England journal of medicine. 2015 Nov 26;373(22):2117-28. [PubMed]

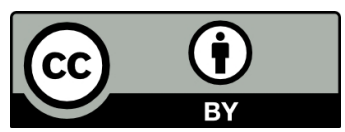

Submit your manuscript to Boston science publishing journal and benifit from:

- Convenient online submission

- Rigorous peer review

- Immediate publication on acceptance

Open access: articles freely available online

- High visibility within the field

- Retaining the copyright to your article

Submit your manuscript at \pm bostonsciencepublishing.us 